\title{
Implementasi Sistem Penjualan Secara Kredit Pada PT Omega Lestari Mandiri Karawang
}

\author{
Indaryono ${ }^{1}$, Hasmizal $^{2}$, Arif Maulana Yusuf ${ }^{3}$, Fitria Isna Wati ${ }^{4}$ \\ 1,2,3,4 STMIK Rosma Karawang \\ Jln. Kertabumi No. 62 Karawang Barat \\ e-mail: indaryono@dosen.rosma.ac.id, hasmizal@dosen.rosma.ac.id, arif@rosma.ac.id, \\ fitria@mhs.rosma.ac.id
}

\begin{abstract}
Abstrak
Dalam hal pembuatan rekap tagihan atas penjualan jasa service kendaraan secara kredit pada PT Omega Lestari Mandiri seringkali mengalami kesalahan input data, baik dalam tanggal pembuatan rekap mau pun dari potongan harga dan pembuatan SKB. Kesalahan tersebut mengakibatkan proses pengiriman lebih lama sehingga menghambat proses pembayaran dari pelanggan sehingga tidak sesuai dengan harapan perusahaan. Metode penelitian yang digunakan adalah SDLC (System Development Life Cycle) menggunakan pendekatan waterfall yang diawali dengan analisis sistem, desain sistem, pembuatan kode program dan pengujian. Penyusunan sistem penjualan spare part dan jasa secara kredit yang diawali oleh proses perencanaan kebutuhan sistem, dilanjutkan dengan analisa dan proses perancangan sistem berdasarkan dari hasil analisa kebutuhan sistem. Tahap akhir dari penyusunan sistem ini yaitu implementasi perancangan untuk menjadi sebuah sistem yang baru. Penelitian ini menghasilkan sebuah sistem penjualan spare part dan jasa secara kredit berbasis komputer VB.Net dengan SQL Server sebagai databasenya. Hasil keluaran yang diperoleh dari sistem ini adalah data penjualan kredit yang terkait dengan faktur penjualan dan kontrabon. Dengan dibuatnya sistem penjualan spare part dan jasa secara kredit ini diharapkan dapat mempermudah untuk melakukan proses penjualan dan penagihan piutang, terhindar dari kesalahan input dan dapat mengefektifkan waktu penginputan dan penghitungan pph pasal 23.
\end{abstract}

Kata Kunci : Penjualan Kredit, Utang, perancangan sistem, Vb.Net

\begin{abstract}
In terms of making a recap of invoices for the sale of vehicle service services on credit, PT Omega Lestari Mandiri often experiences data input errors, both in the date of making the recap or from price discounts and making SKB. The error resulted in the delivery process taking longer so that it hampered the payment process from the customer so that it was not as expected by the company. The research method used is SDLC (System Development Life Cycle) with a waterfall approach model which begins with system analysis, system design, program code generation and testing. The preparation of a system for selling spare parts and services on credit begins with the system requirements planning process, followed by an analysis and system design process based on the results of the system requirements analysis. The final stage of the process of compiling this system is the implementation of the system design into a new system. The results of this study resulted in a system of selling spare parts and services on credit based on a VB.Net computer with SQL Server as the database. The output obtained from this system is credit sales data associated with sales invoices and contrabon. With the creation of a sales system for spare parts and services on credit, it is hoped that it will make it easier to carry out the sales and collection process for accounts receivable, avoid input errors and can streamline the inputting time and calculating income tax article 23.
\end{abstract}

Keywords: Credit Sales, Debt, system design, Vb.Net 


\section{Pendahuluan}

Salah satu tujuan utama perusahaan setelah memberikan jasanya adalah untuk mendapatkan keuntungan yang sebesar besarnya, semua perusahaan dapat mengawasi pelaksanaan proses penjualan dalam perusahaannya dengan baik, sehingga kegiatan penjualan yang terkendali dalam perusahaan dapat meningkatkan keuntungannya, selain mempunyai sistem penjualan yang sudah cukup baik, perusahaan harus memiliki sistem penjualan dan penagiha piutang yang baik disebabkan banyak perusahaan pengguna barang dan jasa membutuhkan waktu dalam melakukan pembayaran pada saat mereka melakukan transaksi dalam jumlah besar(Dari \& Pratiwi, 2018)(Lestari \& Ratna, 2020). Piutang adalah sebuah unsur penting yang perlu diperhatikan perusahaan. Piutang yang prosesnya terhambat dapat membuat kesulitan bagi perusahaan dalam mengelola aktivitas operasional perusahaan dalam keseharian(Kusumaratri \& Purwanto, 2020). Hal ini disebabkan kurang nya transaksi tunai yang terjadi di perushaan.

PT Omega Lestari Mandiri adalah badan usaha yang bergerak dalam bidang jasa pelayanan services dan pemeliharaan kendaraan bermotor roda empat dan merupakan bengkel perwakilan ASTRA untuk mobil merek Daihatsu dan Isuzu. PT Omega Lestari Mandiri didirikan pada tahun 1992 yang beralamat di Karawang tepatnya di jalan Kertabumi no 38. PT Omega Lestari Mandiri merupakan salah satu perusahaan yang melakukan penjualan spare part dan jasa secara tunai maupun kredit. Untuk penjualan kredit PT Omega Lestari Mandiri hanya menerima perusahaan yang membuat $M O U$.

Sistem akuntansi penjualan spare part dan jasa secara kredit yang dilakukan PT Omega Lestari Mandiri meliputi prosedur penyetujuan pembuatan Memorandum of Understanding (MOU) dengan ketentuan melengkapi surat-surat yang dibutuhkan, setelah MOU dibuat service advisor akan menerima surat perintah kerja (SPK) dari pelanggan. Setelah diterimanya SPK tersebut service advisor akan melakukan pemeriksaan. Setelah selesai melakukan pemeriksaan service advisor akan mengkonfirmasi kepada pelanggan apabila ada penggantian suku cadang. Atas kerusakan yang terjadi dan atas dasar SPK tersebut bagian service advisor akan membuat Work Order (WO) untuk memberikan perintah kepada mekanik agar segera melakukan perbaikan. Setelah perbaikan selesai dikerjakan maka bagian gudang / spare part akan membuat faktur penjualan yang berisikan spare part dan jasa yang telah dikeluarkan atau dipakai. Setiap tanggal 15 dan tanggal 1 bulan berikutnya bagian Accounting akan membuat rekap faktur penjualan selama satu bulan atau lima belas hari setelah perbaikan dilakukan. Dalam pembuatan rekapan penjualan kredit serta penghitungan pajak PT Omega Lestari Mandiri masih manual, dalam hal pembuatan rekap dan penghitungan pajak dan mencari data yang telah habis masa kreditnya. Untuk mempercepat pembuatan rekap tagihan dan pelayanan di PT Omega Lestari Mandiri. Oleh karena itu PT Omega Lestari Mandiri harus melakukan pengembangan dan perbaikan sistem.

\section{Metode Penelitian}

Metode penelitian yang penulis gunakan dalam merancang aplikasi pada penelitian ini yaitu SDLC (System Development Life Cycle). Menurut Shalahuddin, Model waterfall sering juga disebut dengan model sekuensial linier (sequential linear) atau alur hidup klasik (classic life cycle)(Krishna, Reddy, Madhav, Kumar, \& Amarendra, 2021). Model air terjun merupakan pendekatan alur hidup perangkat lunak secara sekuensial atau terurut yang dimulai dari analisis kebutuhan sistem, desain, pengkodean, pengujan, dan tahap pendukung. Berikut contoh gambar ilustrasi model waterfall dengan fase langkah-langkahnya :

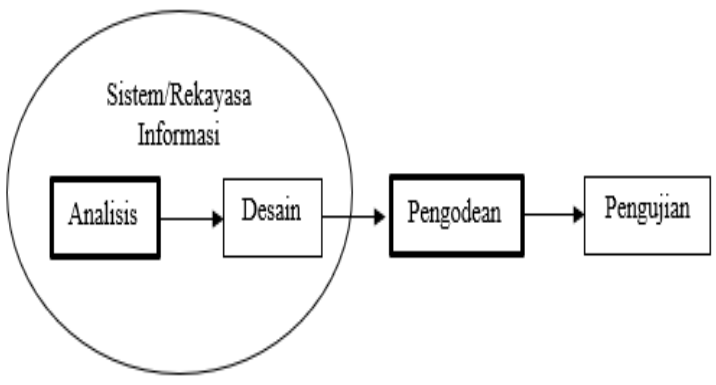

Gambar 1. Tahapan Waterfall

Sumber : Shalahuddin(Krishna et al., 2021)

1. Analisis Kebutuhan Perangkat Lunak Proses untuk pengumpulan kebutuhan yang juga dilakukan secara intensif untuk menspesifikasikan kebutuhan perangkat lunak sehingga dapat 
dipahami perangkat lunak seperti apa yang diperlukan oleh user(Yusuf, Hasmizal, \& Dini, 2021a).

Penelitian yang dilakukan penulis diantaranya :

\section{a. Observasi}

Pengumpulan data yang dapat dilakukan dengan pengamatan langsung pada objek yang akan diteliti dan bagian terkait.

b. Wawancara

Teknik pengumpulan data dengan cara komunikasi Tanya jawab dengan tujuan mendapatkan informasi dan tanggapan secara langsung dari pihak yang terkait. Proses untuk pengumpulan data, keterangan, dan bahan-bahan yang diperlukan dalam penelitian.

c. Studi Pustaka

Teknik pengumpulan data di perpustakaan dengan mengumpulkan atau menggunakan sumber-sumber tertulis yang bersumber pada buku-buku dan dokumen-dokumen yang berkaitan dengan masalah yang diteliti

2. Desain sebagai landasan teori.

Desain perangkat lunak adalah proses multi langkah yang fokus pada desain pembuatan program perangkat lunak termasuk struktur data, arsitektur perangkat lunak, representasi antarmuka, dan prosedur pengodean(Sadiah, Indaryono, \& Yusuf, 2021). Tahap ini mentranslasi kebutuhan perangkat lunak dari tahap analisis kebutuhan ke representasi desain agar dapat diimplementasikan menjadi program pada tahap selanjutnya.

3. Pembuatan Kode Program

Tahap ini desain harus ditranslasikan ke dalam program perangkat lunak. Hasil dari tahap ini adalah program komputer sesuai dengan desain yang telah dibuat pada tahap desain(Sitanggang \& Hakim, 2020). Dalam merancang program penulis menggunakan bahasa pemrograman VB .Net.

4. Pengujian

Pengujian fokus pada perangkat lunak secara dari segi lojik dan fungsional dan memastikan bahwa semua bagian sudah diuji(Permatasari, 2020). Hal ini dilakukan untuk meminimalisir kesalahan (error) dan memastikan keluaran yang dihasilkan sesuai dengan yang diinginkan.

\section{Hasil dan Pembahasan}

\subsection{Diagram Alir Data}

Diagram aliran data adalah suatu model yang menggambarkan aliran data dan proses untuk mengolah data dalam suatu sistem(Yusuf, Hasmizal, \& Dini, 2021b). Diagram ini menjelaskan urutan dari prosedur-prosedur yang ada di dalam sistem. Sistem yang diusulkan telah terkomputerisasi, lebih mudah digunakan, keamanan data terjaga, tidak akan memakan waktu yang lama dalam mengolah data. Karena didalamnya telah disediakan pencetakan laporanlaporan dan fasilitas lainnya yang memudahkan user untuk menggunakan sistem ini. 


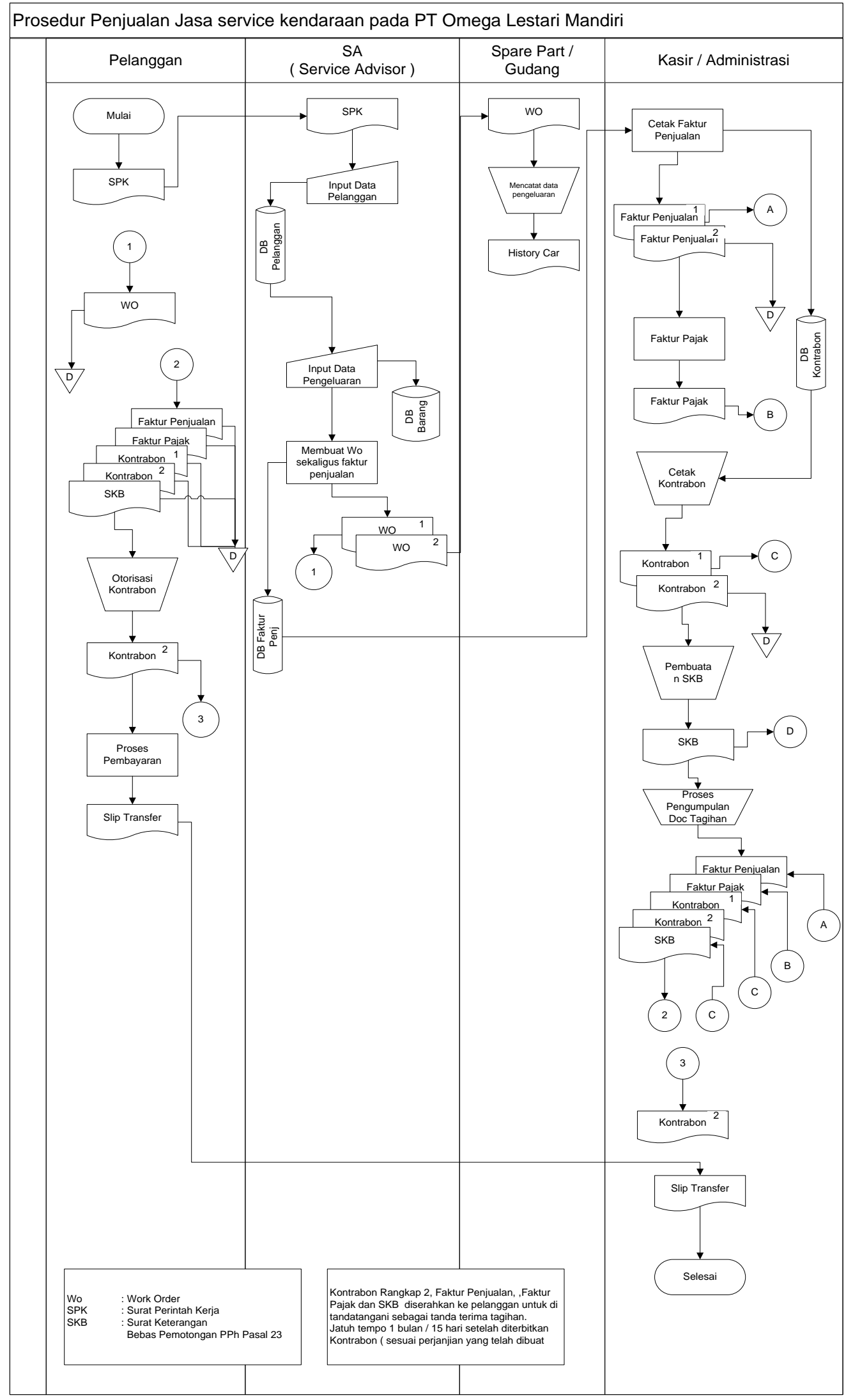

Gambar 2. Flow Sistem 


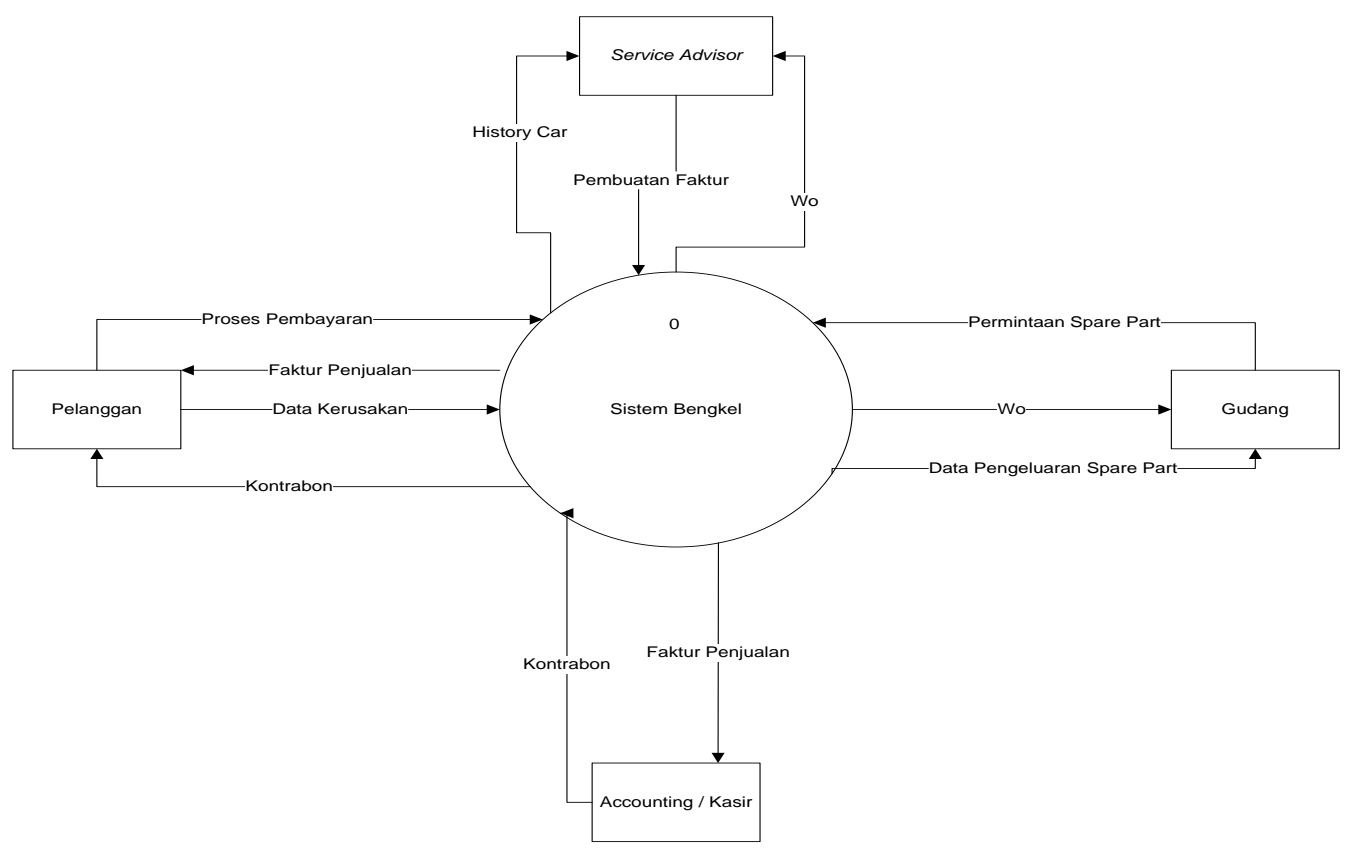

Gambar 3. Diagram Kontek

Pembuatan sistem informasi secara umum atau menyeluruh, DFD bertujuan memberikan gambaran pada sistem analisis pembuatan program mengenai masukan (input) kedalam proses dan apa yang akan dihasilkan keluaran (output).

\subsection{Implementasi Sistem}

Tahapan ini merupakan tahapan yang cukup penting, dimana penerapan aplikasi yang telah dirancang terhadap sistem yang berjalan. Pada tahapan ini kita dapat melihat apakah aplikasi sudah sesuai dengan kebutuhan user atau belum.

1. Form Login

Form login bertujuan untuk mengakses suatu program, hanya karyawan yang telah memiliki user dan password yang bisa mengakses sistem.

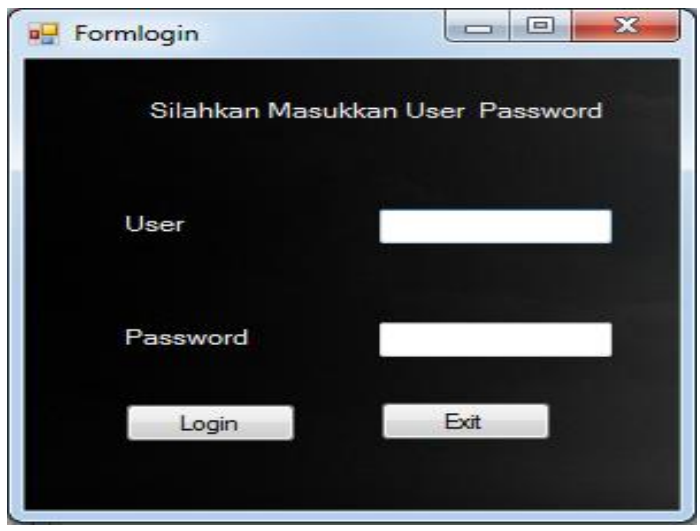

Gambar 4. Form Login
2. Form Menu Utama

Form menu utama bertujuan untuk menampilkan sub menu yang ada dalam program.

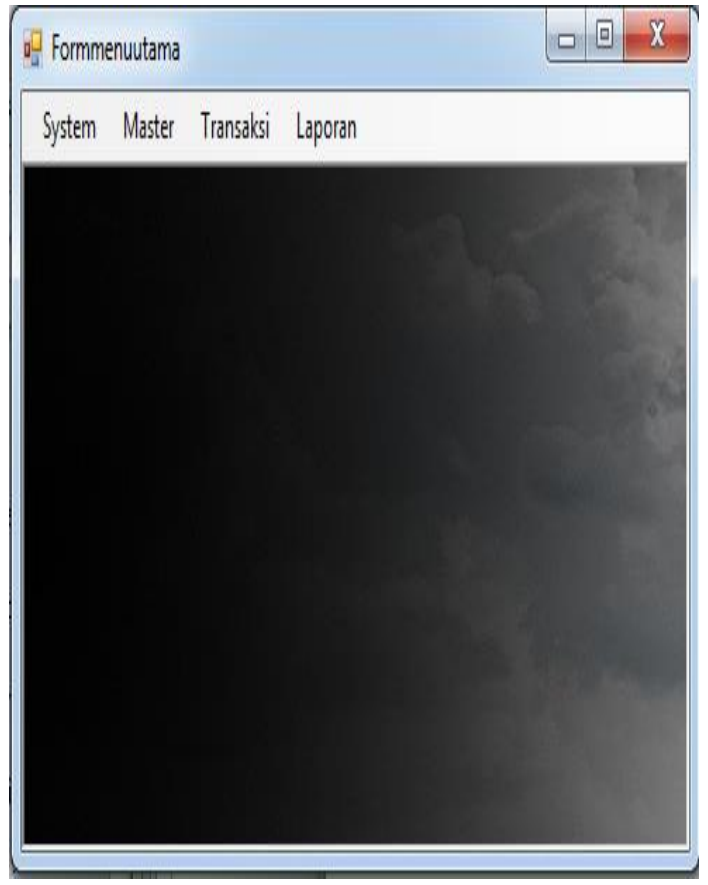

Gambar 5. Form Login 
3. Form Spare Part

Form Spare Part untuk menambah maupun mengedit Data Spare Part

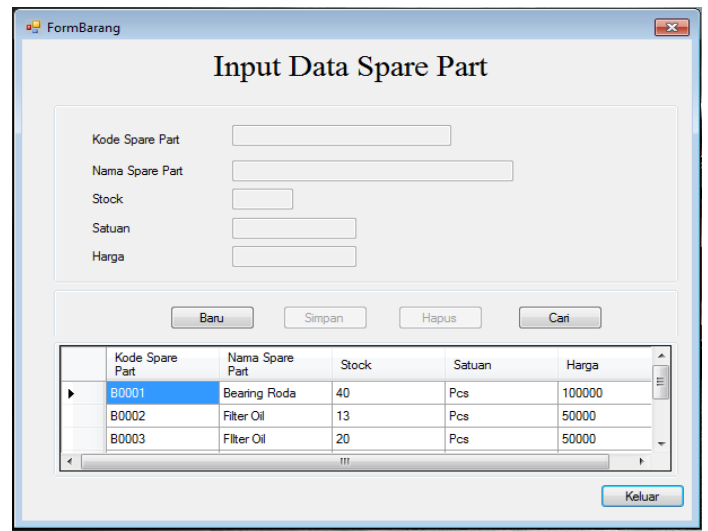

Gambar 6. Form Spare Part

4. Form Jasa

Form Jasa untuk menambah maupun mengedit data jasa

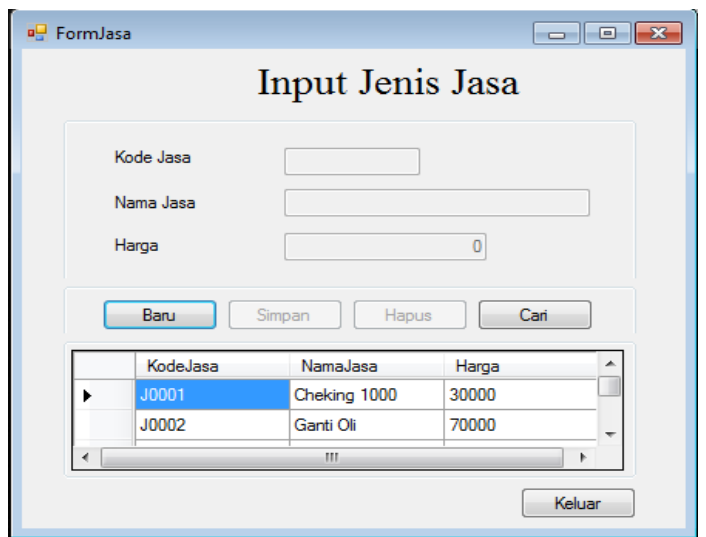

Gambar 7. Form Jasa

5. Form Pelanggan

Form pelanggan untuk mencari menambahkan maupun mengedit data pelanggan

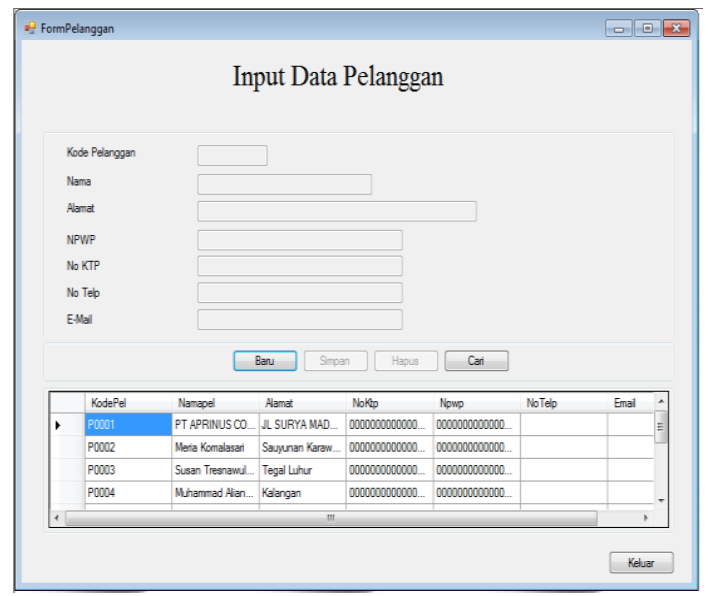

Gambar 8. Form Pelanggan

6. Form Work Order
Form work order ini untuk menginput jenis pekerjaan dan barang/spare part apa saja yang harus dikeluarkan

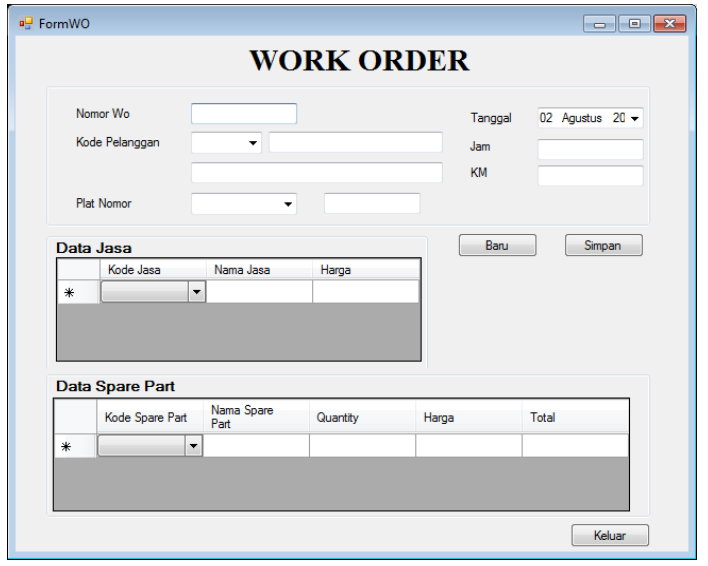

Gambar 9. Form Work Order

7. Form Data Piutang

Form Data piutang untuk mencatat pembayaran piutang yang diterima oleh perusahaan atas pembayaran piutang dari pelanggan yang melakukan pembelian secara kredit

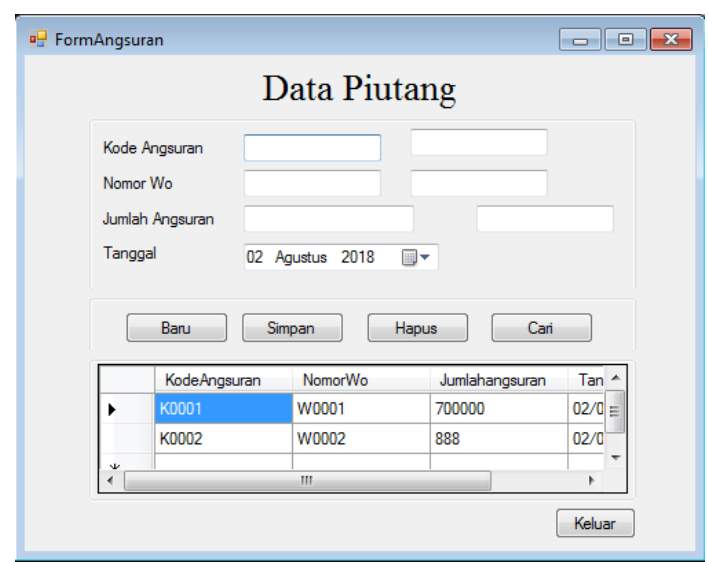

Gambar 10. Form Data Piutang

8. Faktur Penjualan

Output Faktur Penjualan berfungsi untuk menampilkan hasil akhir dari work order

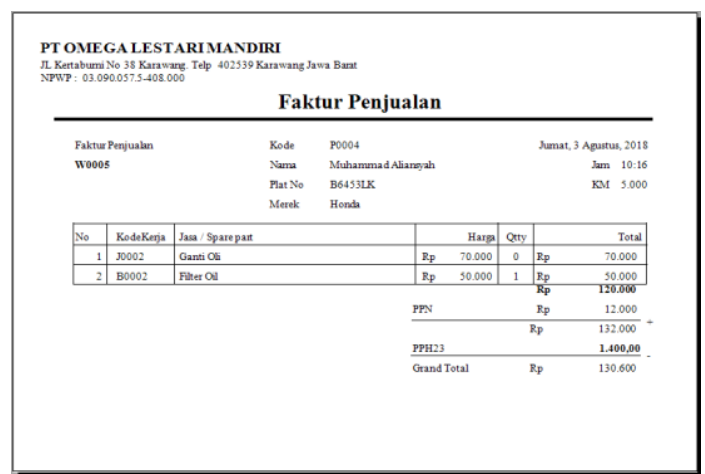

Gambar 11. Faktur Penjualan 


\subsection{Pengujian Sistem}

Berikut ini adalah hasil pengujian aplikasi penjualan kredit barang menggunakan metode Black Box.

\begin{tabular}{|c|c|c|c|c|}
\hline No & $\begin{array}{l}\text { Fungsi yang } \\
\text { diuji }\end{array}$ & Cara pengujian & $\begin{array}{l}\text { Hasil yang } \\
\text { diharapkan }\end{array}$ & $\begin{array}{l}\text { Hasil } \\
\text { Pengujian }\end{array}$ \\
\hline 1 & Form Login & $\begin{array}{l}\text { Pada Form ini } \\
\text { menampilkan } \\
\text { halaman loginuntuk } \\
\text { masuk ke menu } \\
\text { utama }\end{array}$ & $\begin{array}{l}\text { Menampilkan } \\
\text { halaman login dan } \\
\text { berhasil masuk ke } \\
\text { dalam program } \\
\text { sebagai admin }\end{array}$ & Selesai \\
\hline 2 & $\begin{array}{l}\text { Form } \quad \text { Menu } \\
\text { Utama }\end{array}$ & $\begin{array}{l}\text { Seteah berhasil } \\
\text { masuk, maka akan } \\
\text { menampilkan } \\
\text { halaman } \\
\text { utama }\end{array}$ & $\begin{array}{l}\text { Menampilkan } \\
\text { halaman menu } \\
\text { utama }\end{array}$ & Selesai \\
\hline 3 & Form Pelanggan & $\begin{array}{l}\text { memilih } \\
\text { pelanggan }\end{array}$ & $\begin{array}{lr}\text { Menginput } & \text { dan } \\
\text { mencari } & \text { data } \\
\text { pelanggan } & \\
\end{array}$ & Selesai \\
\hline 4 & Form Spare Part & $\begin{array}{l}\text { Memilih } \\
\text { spare part }\end{array}$ & $\begin{array}{l}\text { Untuk menginput } \\
\text { dan mencari data }\end{array}$ & Selesai \\
\hline 5 & Form Jasa & Memilih toolbar jasa & $\begin{array}{l}\text { Untuk menginput } \\
\text { dan mencari data } \\
\text { jasa }\end{array}$ & Selesai \\
\hline 6 & Form Wo & Memilih toolbar Wo & $\begin{array}{l}\text { Untuk Menginput } \\
\text { data wo }\end{array}$ & Selesai \\
\hline 7 & $\begin{array}{l}\text { Form } \\
\text { RptFakturPenjual } \\
\text { an }\end{array}$ & $\begin{array}{l}\text { Menampilkan data } \\
\text { Faktur Penjualan }\end{array}$ & $\begin{array}{l}\text { Berhasil } \\
\text { menampilkan } \\
\text { Faktur Penjualan }\end{array}$ & Selesai \\
\hline
\end{tabular}

\section{Kesimpulan}

Berdasarkan dari hasil penelitian yang dilakukanoleh penulis pada PT Omega Lestari Mandiri, Khususnya pada bagian Administrasi, penulis dapat menyimpulkan beberapa hal sebagai berikut :

1. Sistem penjualan kredit pada PT Omega Lestari Mandiri sudah bagus hanya saja masih memerlukan perbaikan pada bagian penginputan kontrabon maupun penghitungan pph pasal 23 agar tidak memakan banyak waktu dalam pembuatan kontrabon.

2. Segala prosedur penjualan jasa secara kredit dari pembuatan MOU Memorandum Of Understanding, Penerimaan SPK , Pembuatan Work Order, pembuatan faktur penjualan, pembuatan faktur pajak, pembuatan SKB dan pembuatan rekap tagihan atau kontrabon sampai dengan pengiriman tagihan
3. Dalam melakukan pembuatan rekapan penjualan kredit PT Omega Lestari Mandiri masih menggunakan cara manual sehingga masih perlu banyak ketelitian untuk penginputannya. Sebuah sistem telah dibuat untuk mengurangi terjadinya kesalahan input

4. Sebuah sistem penjualan spare part dan jasa secara kredit menggunakan Microsoft Visual Studio 2008 ( VB.Net ) telah dibuat untuk mempermudah transaksi penjualan serta pembuatan rekap tagihan

\section{Referensi}

Dari, W., \& Pratiwi, L. I. (2018). Sistem Informasi Penjualan Alat Musik Menggunakan Model Waterfall. Jurnal Khatulistiwa Informatika.

Krishna, M. V. L. P., Reddy, G. S., Madhav, M. V., Kumar, J. P., \& Amarendra, K. (2021). Component based software development (SDLC). Turkish Journal 
of Physiotherapy and Rehabilitation.

Kusumaratri, R. D., \& Purwanto, P.-. (2020). PERANCANGAN SISTEM INFORMASI AKUNTANSI PIUTANG PADA CV MENANG SENTOSA. SISTEMASI.

https://doi.org/10.32520/stmsi.v9i2.712

Lestari, N., \& Ratna. (2020). Sistem Informasi Akuntansi Penjualan. Journal of Chemical Information and Modeling.

Permatasari, D. I. (2020). Pengujian Aplikasi menggunakan metode Load Testing dengan Apache JMeter pada Sistem Informasi Pertanian. Jurnal Sistem Dan Teknologi Informasi (JUSTIN). https://doi.org/10.26418/justin.v8i1.344 52

Sadiah, J., Indaryono, I., \& Yusuf, A. M. (2021). Sistem Informasi Akuntansi Penggajian Berbasis Vb.Net Pada PT BANK PERKREDITAN RAKYAT (BPR) SANGGABUANA AGUNG KARAWANG. Jurnal Interkom: Jurnal Publikasi IImiah Bidang Teknologi Informasi Dan Komunikasi. https://doi.org/10.35969/interkom.v15i4 80

Sitanggang, I. S., \& Hakim, R. F. (2020) Pendeteksian Penjiplakan Kode Program C dengan Menggunakan Algoritme K-Medoids. Jurnal IImu Komputer Dan Agri-Informatika. https://doi.org/10.29244/jika.7.2.74-83

Yusuf, A. M., Hasmizal, H., \& Dini, N. (2021a). Sistem Informasi Perhitungan Penyusutan Aktiva Tetap Menggunakan Metode Garis Lurus Berbasis Vb.Net Pada CV Ginanjar Sejahtera Mandiri Karawang. Jurnal Interkom: Jurnal Publikasi IImiah Bidang Teknologi Informasi Dan Komunikasi.

https://doi.org/10.35969/interkom.v16i1 .86

Yusuf, A. M., Hasmizal, H., \& Dini, N. (2021b). Sistem Informasi Perhitungan Penyusutan Aktiva Tetap Menggunakan Metode Garis Lurus Berbasis Vb.Net Pada CV Ginanjar Sejahtera Mandiri Karawang. Jurnal Interkom: Jurnal Publikasi IImiah Bidang Teknologi Informasi Dan Komunikasi.

https://doi.org/10.35969/interkom.v16i1 .95 